\title{
Leadership Style for Millennial Generation, Five Leadership Theories, Systematic Literature Review
}

\section{Christian Wiradendi WOLOR ${ }^{*}$, Ahmad NURKHIN², Yudin CITRIADIN ${ }^{3}$}

\author{
${ }^{1}$ Faculty of Economics, Universitas Negeri Jakarta, Rawamangun Muka Street, Jakarta, Indonesia. \\ Email: christianwiradendi@unj.ac.id \\ ${ }^{2}$ Faculty of Economics, Universitas Negeri Semarang, Sekaran Gunung Pati, Semarang, Indonesia. \\ Email: ahmadnurkhin@mail.unnes.ac.id \\ ${ }^{3}$ Faculty of Tarbiyah and Education, Universitas Islam Negeri Mataram, Dasan Agung Baru, Mataram, Indonesia. \\ Email: yudin.citriadin@uinmataram.ac.id \\ *Corresponding Author
}

\author{
Received: 20.05.2021 Accepted: $25.08 .2021 \quad$ Published: $16.10 .2021 \quad$ DOI: $\underline{10.47750 / Q A S / 22.184 .13}$
}

\begin{abstract}
At present, the employees of the company have started to shift from the old generation to the millennial generation who have very different styles and characteristics compared to the previous generation who have the nature to care only about themselves but are very reliable in terms of technology. Companies must adapt quickly and apply appropriate leadership style techniques to achieve optimal company performance in the midst of dominating millennial generation employees. This article aims to identify effective leadership styles in dealing with millennial generation employees by considering the five current leadership theories in the context of workforce change. This study uses a systematic literature review. Next, it explores the strengths and weaknesses of the five leadership styles for millennial employees to understand the leadership styles that are appropriate for the millennial generation. The conclusion shows that a combination of the five leadership style approaches is needed to accommodate millennial characteristics that differ from previous generations under the name of a civilized innovation leadership approach.
\end{abstract}

Keywords: Leadership Style, Millennial Generation, Five Leadership Theories, Systematic Review

\section{Introduction}

The industrial revolution is described as artificial intelligence, innovation, super technology, and genetic engineering. This era shows the physical changes in the world very quickly in changing human lifestyles. This is due to the effects of the use of modern technology. At present, the company has begun to enter the millennial generation and replaces the baby boomer generation to the $\mathrm{X}$ generation. In terms of work, there are differences regarding the way of thinking and values between millennials and other generations (Moorthy, 2014). As a result, to achieve optimal performance, companies must carry out various effective ways. (Putriastuti \& Stasi, 2019). Negatively mentioned the millennial generation only cares about their image, and vice versa the millennial generation has a positive aspect too, namely high creativity, closely with technology.

Other studies show that there is a change in the work value of millennials compared to generation $x$ and baby boomers, namely the desire for high work-life balance, job satisfaction and the desire to move companies or the disloyalty of the company that is not the same between millennials with generation $x$ and generation baby boomer (Anderson, Baur, Grif, \& Buckley, 2016), (Putriastuti \& Stasi, 2019). Apart from various points of view, it's clear that the millennial generation is different from the previous generation (Anderson et al., 2016).

The millennial generation is more difficult to make loyal and committed to the industry because of its character who likes freedom, flexibility, dialogue, open communication with superiors and colleagues, and the use of technology. Companies must pay attention and think about the importance of changing and adapting a manager's current leadership strategy in supervising his staff who, on average, have been filled with millennials (Valenti, 2019), (Putriastuti \& Stasi, 2019), (Mansor, Mun, Farhana, \& Tarmiz, 2017). The role of a leader is very important and decisive in achieving the company's vision, directing the team underneath, motivating, empowering employees to achieve organizational goals, leadership in the organization requires skills, especially in a competitive work environment (Solaja \& Ogunola, 2016).

These results suggest that this generational difference may require adaptation to current leadership theory. Leaders play a major role in retaining employees, motivating, and improving employee performance for two main reasons. First, Millennials tend to work with their style without interference from others. Second, millennial employees have a different value from previous generations in terms of work where they will be very easy to find new jobs if they feel uncomfortable and their needs are not met (Anderson et al., 2016). The traditional leadership model is not the best method for implementing sustainable change (Al-Khasawneh \& Futa, 2013). Entrepreneurs need to understand what this generation expects from all aspects of their work, from leadership preferences. Understanding what distinguishes Millennials from other generations is important for developing future leaders (Moorthy, 2014).

This article aims to identify effective leadership styles in 
dealing with the millennial generation in the industrial world. By using the five current leadership theories related to the workforce, we strive to create a framework to guide future research on effective leadership styles in dealing with millennials. Leaders must identify and adapt to the changing needs of increasingly high employees, where employees will not participate in an optimal organizational life if the majority of millennial needs are not met.

\section{Literature Review}

\subsection{Leadership}

Leadership is one's ability to influence, decide what you want to do, and make others do it too (Moorthy, 2014), (Dartey-baah, 2015). Leadership is not a rank that must be better than others, but rather a responsibility to achieve a higher organizational vision (Solaja \& Ogunola, 2016). Leadership is how a person can prepare his organization to cope with the changes that will always come (Ratcliffe \& Ratcliffe, 2015).

\subsection{Participative Leadership}

A participatory leader, ie a leader allows employees below him to participate in making decisions, opinions, and consideration of ideas from subordinates (Chou, 2012). This leader encourages the participation and contribution of each member to increase employee commitment which leads to better decision quality (Amanchukwu, Stanley, \& Ololube, 2015). This will also create a sense of belonging to the organization (Salahuddin, 2010).

\subsection{Transforsactional (Transformational- Transactional) Leadership}

Transformational leaders are leaders who have a clear vision for the future of their organization, behave in a good manner (Solaja \& Ogunola, 2016), motivate employees (Anderson et al., 2016), meet the needs of each employee through education, coaching, mentoring activities (Putriastuti \& Stasi, 2019), and focus on growth and actualization (Mansor et al., 2017). The current transformational leadership model in which a leader can achieve organizational goals and help millennial generation employees achieve their personal goals because it is individualistic and selfish (Anderson et al., 2016), especially the millennial generation likes challenges (Moorthy, 2014).

The transactional leadership approach is established based on an agreement between a leader and his employees where each party fulfills an agreed transaction agreement to ensure the continuity of the relationship between them through the bureaucratic system, policies, regulations (Mansor et al., 2017). Transactional leadership emphasizes a reward and punishment system in the form of a reward system, salary, compensation commission (Solaja \& Ogunola, 2016) obtained, and punishment if the performance is not good (Dartey-baah, 2015). Transactional leadership emphasizes extrinsic motivation, while transformational leadership emphasizes intrinsic motivation (Anderson et al., 2016).

\subsection{Relational Leadership Theories}

The leadership process occurs when leaders and employees build positive social relationships (Putriastuti \& Stasi, 2019). This leadership focus not only on aspects of the job but also pay attention to aspects of employee interpersonal (Moorthy, 2014). When employees and leaders have a high exchange relationship, employees and organizations have a positive impact on career advancement for employees, employee retention (Almaaitah, Harada, Sakdan, \& Almaaitah, 2017) and commitment to the organization (Anderson et al., 2016). But it must also be considered related to the rules where the parties must obey the agreed rules.

Several previous studies have only focused on reciprocal relationships, but do not include rules in them that aim to arise trust from employees, commitment, and loyalty. Respect will disappear when the leader deceives or has a specific purpose and is not being sincere in forming a relationship (Hangeior, Ihagh, \& Esiebugie, 2016). In other words, a social exchange relationship is a link where an organization can look after its employees and have a strong relationship that will produce a positive attitude and effective work behavior from employees (Cropanzano \& Mitchell, 2014).

\subsection{Ethical/Moral Leadership Theories}

This theory refers to understanding ethics, behaving ethically and promoting moral behavior and good values among their followers (Anderson et al., 2016), (Moorthy, 2014) through a reward system (reward and discipline) (Yozgat \& Meşekıran, 2016), through interpersonal relationships and personal actions based on altruistic motives rather than mere ego (Ahmad, Gao, \& Hali, 2017).

Ethical leadership includes the characteristics of a moral leader with certain characteristics, namely: honesty, integrity, openness, respect, principled in making decisions (Ahmad et al., 2017), communicate with their employees about ethics, set clear ethical standards and use gifts and penalties to ensure that standards are followed (Brown \& Treviño, 2006). Ethical leadership focuses on leaders influencing their employees to do the right thing (Monahan, 2012). Being a role model in ethical behavior in daily life is one way to promote ethical behavior. Employees see leaders behave ethically, employees can learn to distinguish between right and wrong actions in certain situations, make fair and balanced decisions (Yozgat \& Meşekıran, 2016). Employees can learn through the actions of their leaders. Employees will pay attention to the behavior of their leaders when they feel their leader is a worthy example (Anderson et al., 2016).

\subsection{E-Leadership Theories}

The era of digitalization created a revolution in the industrial world that shaped the reconstruction of the concept of leadership which was labeled as E-Leadership as a result of the development of information technology (Mohammad, 2009). Eleadership theory studies leadership in work environments that support technology that has an impact on potential interactions and electronic communication networks (Putriastuti \& Stasi, 2019). It can be said that through information technology, eleadership achieves organizational goals (Iriqat \& Khalaf, 2017). Technology is becoming popular in every organization as a tool to encourage collaboration and produce knowledge sharing among workers such as e-mail, teleconferences (Solaja \& Ogunola, 2016).

E-Leadership has roles and responsibilities where leaders can communicate with their employees even though they are not in the same office and must understand new technology to meet employee needs and build relationships between employees (Mohammad, 2009).

\subsection{Millennial Generation}

There is a shift in the current generation in the world of work. Where the millennial generation begins to replace the baby boomer generation and generation $\mathrm{x}$. The millennial generation will reach $75 \%$ of the total workforce today by 2025 . 
Characteristics and nature of the millennial generation that is very intelligent with technology (Solaja \& Ogunola, 2016), multitasking, want freedom and flexibility in working time and tends to be open to communicating with leaders (Putriastuti \& Stasi, 2019), (Moorthy, 2014).

Millennials have a negative aspect that is not loyal to the company. They are willing to leave their jobs and look for better career opportunities for the millennial generation, which means a lack of commitment to the organization (Moorthy, 2014). Organizational culture is not related to the millennial culture itself (Putriastuti \& Stasi, 2019). Millennials seem to be more individualistic and have less concern for others (Anderson et al., 2016).

Conversely, the millennial generation has positive aspects as well where they are very optimistic, have confidence and do not hesitate to give the best performance (Wolor, Pratama, Aditya, $F$, \& Purwana, 2020) and maximum to get promotions and awards from the company (Moorthy, 2014). Millennials are thirsty for the challenge of achieving what they want (Putriastuti \& Stasi, 2019); (Anderson et al., 2016). Extrinsic compensation in terms of bonuses, incentives are worth considering because the millennial generation is happy and enthusiastic to reach them. They are smart in financial management (Putriastuti \& Stasi, 2019).

The millennial generation is different from the previous generation. Millennials like to work everywhere, they don't have to be in the office and don't need to work overtime. They want to work flexibly which is not measured by time. They want a worklife balance where there is a balance between personal life and work life. That way, they will do optimal performance (Putriastuti \& Stasi, 2019).

The results of several studies show that Millennials are happy with something instant. They want to be promoted immediately and like compensation rewards. They tend to be motivated by extrinsic rewards rather than intrinsic. (Anderson et al., 2016).

\subsection{Leadership and Millennial Generation}

Previous studies say the Millennials want leadership figures who build interpersonal relationships, listen, pay attention, communicate well, and give trust to millennials to prove their performance (Putriastuti \& Stasi, 2019). The millennial generation prefers a leadership style that emphasizes the acceptance of subordinate opinions, ranging from decisionmaking suggestions, communication, and feedback from employees to leaders (Valenti, 2019). They like to be allowed to express their potential, participate in organizational decision making contributions, but for work processes to remain within the prescribed work procedures (Solaja \& Ogunola, 2016).

\section{Methodology}

This research is a systematic literature review using the PRISMA (Preferred Reporting Items for Systematic Reviews and Meta-analysis) method which is carried out systematically by following the correct stages or research protocols. A systematic review is a research method that aims to evaluate, identify, analyze all previous research results that are related and relevant to a particular topic, particular research, or the latest phenomenon of concern. The facts presented are comprehensive and balanced because systematic reviews are used to synthesize relevant research findings. The systematic literature review includes the following steps: Formulating research questions, conducting systematic literature review searches, screening and selecting suitable research articles, Conduct analysis and synthesis of qualitative findings, Implement quality control, Prepare a final report (Perry \& Hammond, 2002).

A qualitative approach is used to frame, analyze, and provide comprehensive solutions in the form of strategic models for the Company in improving millennial generation performance (Berkah \& Sawarjuwono, 2019). After an in-depth review of the literature for analysis, several articles were selected as the main corpus. Various scientific articles are taken from special journals that have helped build characterization of the most prominent elements that illustrate effective leadership style and the millennial generation, based on several important points explained by different authors (Moreno, Lafuente, Carreón, \& Moreno, 2017).

The procedure of this systematic review consists of several steps, namely 1) compile Background and Purpose (Background and objectives), 2) Research Question, 3) Searching for the literature 4) Selection Criteria 5) Data Extraction Strategy 6) Assess Quality of Primary Studies, 7) Data Synthesis (Vasconcelos et al., 2013; Wahono, 2015).

\subsection{Research Question on Literature Review}

\begin{tabular}{|l|l|l|}
\hline ID & Research Question & Motivation \\
\hline RQ1 & $\begin{array}{l}\text { Which journals are the most significant } \\
\text { related to leadership styles? }\end{array}$ & $\begin{array}{l}\text { Identify the most significant journals in the } \\
\text { field of leadership style }\end{array}$ \\
\hline RQ2 & $\begin{array}{l}\text { Who is the most active and influential } \\
\text { researcher on leadership style theory? }\end{array}$ & $\begin{array}{l}\text { Identification of the most active and } \\
\text { influential researchers who contributed } \\
\text { much to the field of leadership style } \\
\text { theory research }\end{array}$ \\
\hline RQ3 & $\begin{array}{l}\text { What research topics do researchers } \\
\text { choose in the field of leadership style } \\
\text { prediction for millennials? }\end{array}$ & $\begin{array}{l}\text { Identify research topics and trends in } \\
\text { leadership style for millennials }\end{array}$ \\
\hline RQ4 & $\begin{array}{l}\text { What methods of approach are used to } \\
\text { deal with millennials? }\end{array}$ & $\begin{array}{l}\text { Identify strengths and weaknesses for } \\
\text { effective leadership style prediction } \\
\text { methods in dealing with millennials }\end{array}$ \\
\hline
\end{tabular}

Table 1. Research Questions on Literature Review

\subsection{Searching for the literature}

This research was conducted in February-March 2020 in the city of Jakarta. Search for relevant research articles with the topic of this research conducted using keywords: Leadership Style, Millennial generation. To select articles we use the following databases: Scopus, DOAJ, Proquest, Ebsco. 


\section{GENERAL MANAGEMENT}

Adjustments were made in the strategy used to find the article, the inclusion criteria were predetermined, to maintain consistency in finding the article and avoiding possible bias.

\subsection{Selection Criteria}

Inclusion criteria used to guide the search and selection of articles are research in English (IC1), complete articles published in national and international journals in the 2000-2020 period, indexed in the database used, focused on leadership style and millennial generation (IC2). (Fig1). After getting a sample, the selected article is then analyzed for the collection of relevant information. Analysis and synthesis of data extracted from the article are made descriptively to observe, describe, and classify data to gather knowledge generated on the themes explored in the meta-synthesis. Therefore, meta-analysis can produce new concepts through a synthesis of study content surveyed to transform some qualitative studies into new studies and contribute to the dissemination of scientific knowledge (Vasconcelos et al., 2013).

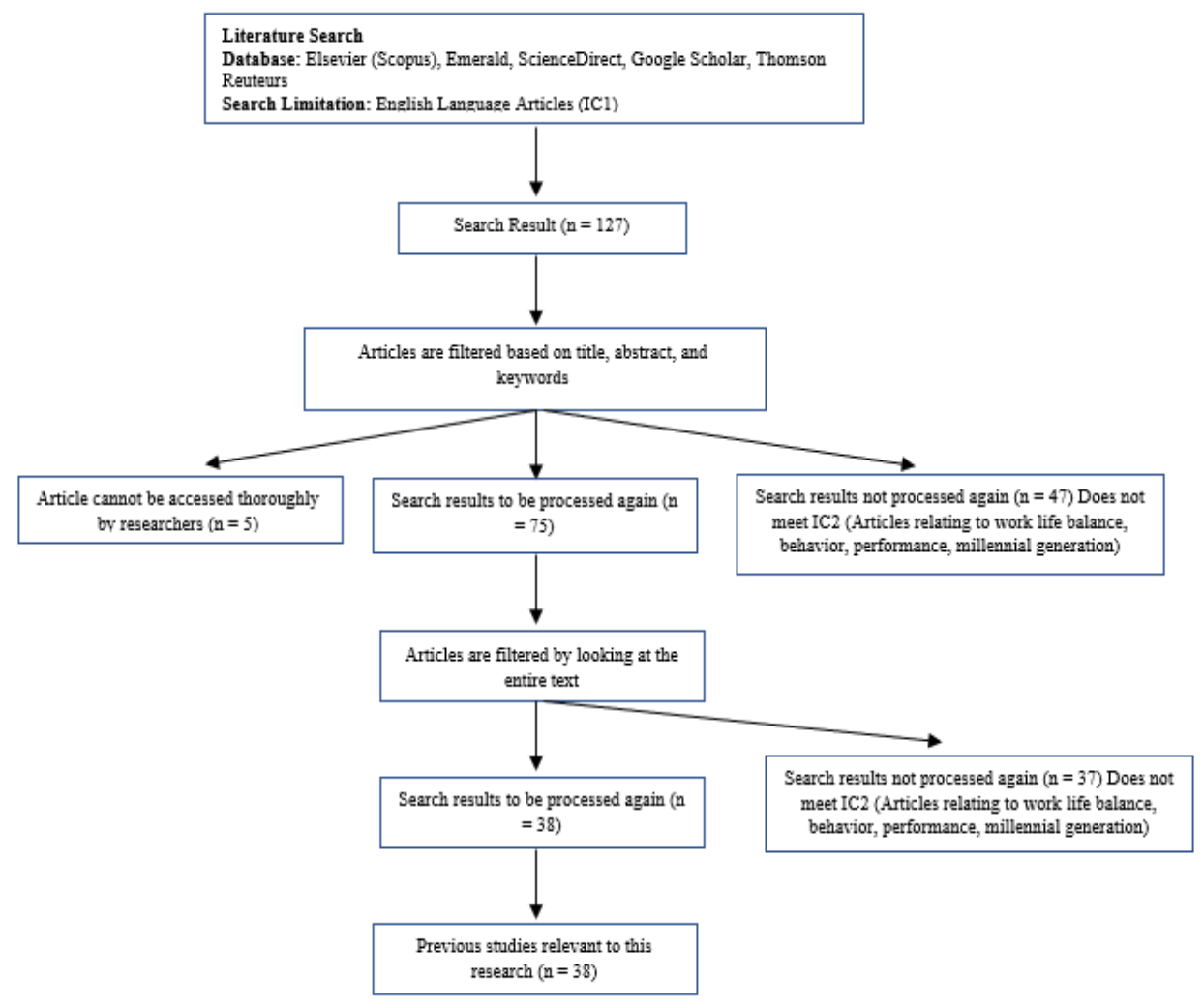

Fig. 1: Prisma Flow Diagram Systematic Review

\subsection{Data Extraction, Assess Quality of Primary Studies, and Data Synthesis}

The main study chosen is then extracted to collect data that contributes to answering research questions. Assessment of research quality can be used to guide the interpretation of the synthesis findings and to determine the conclusions described. The purpose of data synthesis is to gather evidence from selected studies to answer research questions.

\section{Discussion}

From digital searches, 127 articles were found in a predetermined database. 89 were excluded because they did not meet the inclusion criteria. The theme "Leadership Style Gaps in the Millennial Generation" was built as a new statement from this meta-analysis because 38 articles discussed five approaches to leadership style to deal with millennials with various advantages and disadvantages.

Other generation gaps may pose some challenges for leaders in general, especially in today's industry. Millennial generation employees have a relationship that is almost contrary to previous generations. Millennials have an individualistic and arrogant nature who consider themselves capable and do not need direction from others, but on the other hand, they need positive feedback for the development of their attitudes and performance. With the nature of the millennial generation like this can make leaders confused in acting and behaving. (Anderson et al., 2016). Current leadership theory has not been able to overcome this problem.

First, based on some analysis of articles from chou, Valenti, Salahuddin, and Amanchukwu. A participatory approach in which the results of previous studies found that the millennial generation shows participation in the workplace (Chou, 2012), through their willingness to provide ideas, ideas, and not hesitate to criticize the policies of their superiors. Therefore, organizations can eliminate organizational obstacles such as long bureaucracy. Commitment to the organization is fairly low for the millennial generation compared to the previous generation due to their disloyal attitude and will move to a new job if their expectations are not met (Valenti, 2019). This participative leader will increase commitment and a high sense of ownership where the millennial generation tends to be disloyal to the organization (Amanchukwu et al., 2015), (Salahuddin, 2010). The challenges of participatory leadership in which, the 
charisma of a leader is needed so that employees are not controlled and able to be the last executor in decision making whatever the risk.

Second, based on some analysis of articles from putriastuti, dartey, Anderson, and khasawneh. The transformational approach is likely to be favored by the millennial generation because this generation is motivated by meaningful and challenging work (Putriastuti \& Stasi, 2019), emphasizing individual achievement, creating a vision that inspires (Darteybaah, 2015) wanting feedback from a mentor and given special attention, it is possible to make setting individual goals parallel to the goals of the organization to work well to motivate the millennial generation (Anderson et al., 2016). This is the brainchild of not only transactional leadership but much needed transformational leadership that has a positive influence on performance (Al-Khasawneh \& Futa, 2013) that is, adding longterm extrinsic rewards will motivate the millennial generation to perform well (Anderson et al., 2016).

Third, based on some analysis of articles from putriastuti, chow, anderson, and cropanzano. The relational leadership approach can help deal with the millennial generation. Millennials like leaders who choose interpersonal relationships, listen carefully, and can provide feedback through good communication (Putriastuti \& Stasi, 2019). In particular, the challenge now is that the millennial generation sees relations between people as very different from previous generations where they are accustomed to using technology in communication and relationships. This is certainly by today's globalization, but on the other hand, it will be difficult to build direct emotional relationships (Anderson et al., 2016). Leaders need to ensure that millennials feel their initial contributions. So they can experience satisfaction with their leaders which in turn can improve performance. Given that Millennials prefer to express their thoughts, ideas, and opinions. This can be done using open discussions and panels considering the millennial generation likes to express their opinions, ideas, and thoughts (Chou, 2012). Then the form of support from the organization and openness will increase the relationship of trust and ultimately improve the relationship between the leader of the organization and his employees (Cropanzano \& Mitchell, 2014).

Fourth, based on some analysis of articles from ahmad, brown, monahan, anderson, and yozgat. The ethical leadership approach is difficult to apply to millennials where morality in the workplace is considered less important. Millennials tend not to find advice from ethical leaders (Putriastuti \& Stasi, 2019). Millennials are very interested in extrinsic rewards in the form of compensation, awards. This allows the millennial generation to be tempted to do everything possible even if it is unethical to achieve what it wants to achieve. Especially if organizational leader ethics do not exist by justifying any means to achieve something, as a resulting trust in the leader decreases. This is due to not only selfishness but ignorance (Monahan, 2012). One suggested solution related to ethical leadership is the existence of role models in ethical behavior, adhering to ethical guidelines, and campaigning for ethical culture in organizations (Anderson et al., 2016). Secondly, it is also important to socialize the consequences of unethical actions that can destroy one's career and image and provide knowledge about ethics and training in ethical behavior (Ahmad et al., 2017). Third, it takes a role model of company leaders to provide examples of ethical behavior so that it can be followed by followers (Brown \& Treviño, 2006). Previous studies have suggested that ethical leadership, by promoting, demonstrates ethical behavior, and influences employees to do the right thing (Monahan, 2012) will result in increased job satisfaction and trust in leaders (Yozgat \& Meşekıran, 2016).

Fifth, based on some analysis of articles from ibrahim, iriqat, putriastuti, and Mohammad. The e-leadership theory approach can be effectively applied to the millennial generation because this generation is very close to technology. The application of $E$ leadership can advance the performance of an organization, especially for millennials who are very close to technology in the form of virtual communication relationships and virtual information sharing (Ibrahim, 2015). For example, regular meetings and training are conducted via the internet. This can make employees have flexible working hours, do not have to work in the office, and work overtime. This will create a work-life balance that is important for the millennial generation (Putriastuti \& Stasi, 2019). E-Leadership has a positive impact on organizational commitment and good for the company (Iriqat \& Khalaf, 2017). However, e-leadership theory may not be effective if fully implemented only by using virtual communication tools. The limitations of e-leadership must be considered because the value of Millennials has a strong interpersonal relationship between colleagues, leaders, and subordinates (Putriastuti \& Stasi, 2019). The next challenge is the perception of distributive justice where employees are not physically present in the office (Mohammad, 2009). Therefore we need rules and procedures that enable employees to work but are still in the corridor of discipline and justice for all employees.

As a result of interpretations of research found in selected studies and demonstrated in this meta-analysis, one theory alone is not enough to lead the millennium, a new and more complex leadership theory approach is needed. This insight is important in providing the basis for developing a millennial style approach that is suitable for millennial generation employees. Future leadership theory must be designed to accommodate the characteristics of millennial generation so that it is more optimal to lead the millennium. We recommend a new approach from the five leadership style theories discussed earlier, which is the civilized innovation leadership approach where there are characters who grow and innovate but still prioritize personal relationships that are bound. This is based on the character of the millennial generation who likes change and technology but lacks personal and ethical relationships with others. Civilized Innovation leadership is formed from five elements of leadership style consisting of transformational-transactional, relational, electronic, ethical, participatory.

\section{Conclusion}

In conclusion, this systematic literature review aims to identify and analyze trends, data sets, which are used in research into predicting effective leadership styles in millennials. Based on the inclusion and exclusion criteria designed, finally, 38 articles were selected. This systematic literature review also causes reflections on gaps in the reality of changing characteristics between generations, causing the need for adaptation of leadership styles in organizations. Highlighting the need to explore how effective leadership forms are aimed at strengthening the emotional relationships and performance of employees, especially millennials. Thus, a recommendation arises that there must be a new approach outside the current leadership style theory.

\section{Limitations and Future Research}

The gaps in the appropriate leadership style approach in leading the millennial generation in this paper do not signify that current leadership theories are useless. This study uses a systematic review method. Empirical testing is needed to prove this research. Furthermore, future research can look at the organizational and cultural context to be investigated so that it can add insight into the leadership that is suitable for dealing with millennials. At the very least, these theories need to be adapted 
to cope with changes in employee personality and values, and, to date, there has been little effort to do so. This paper serves as a guide for important variables that need to be considered to lead millennial generation employees.

\section{References}

[1] Ahmad, I., Gao, Y., \& Hali, S. M. (2017). A Review of Ethical Leadership and Other Ethics- Related Leadership Theories. European Scientific Journal, ESJ, 13(29), 10-23. doi: 10.19044/esj.2017.v13n29p10

[2] Al-Khasawneh, A. L., \& Futa, S. M. (2013). The Impact of Leadership Styles Used by the Academic Staff in the Jordanian Public Universities on Modifying Students 'Behavior: A Field Study in the The Impact of Leadership Styles Used by the Academic Staff in the Jordanian Public Universities on Modi. International Journal of Business and Management, 8(1). doi: 10.5539/ijbm.v8n1p1

[3] Almaaitah, M. F., Harada, Y., Sakdan, M. F., \& Almaaitah, A. M. (2017). Integrating Herzberg and Social Exchange Theories to Underpinned Human Resource Practices, Leadership Style and Employee Retention in Health Sector. World Journal of Business and Management, 3(1), 16-34. doi: 10.5296/wjbm.v3i1.10880

[4] Amanchukwu, R. N., Stanley, G. J., \& Ololube, N. P. (2015). A Review of Leadership Theories, Principles and Styles and Their Relevance to Educational Management. Management, 5(1), 614. doi: 10.5923/j.mm.20150501.02

[5] Anderson, H. J., Baur, J. E., Griffith, J. A., \& Buckley, M. R. (2017). What works for you may not work for (Gen)Me: Limitations of present leadership theories for the new generation. The Leadership Quarterly, 28(1), 245-260. doi: 10.1016/j.leaqua.2016.08.001

[6] Berkah, D., \& Sawarjuwono, T. (2019). INHERITANCE WEALTH DISTRIBUTION MODEL AND ITS IMPLICATION TO ECONOMY. Humanities \& Social Sciences Reviews, 7(3), 0110. doi: $10.18510 /$ hssr.2019.731

[7] Brown, M. E., \& Treviño, L. K. (2006). Ethical leadership: A review and future directions. The Leadership Quarterly, 17(6), 595-616. doi: 10.1016/j.leaqua.2006.10.004

[8] Chou, S. Y. (2012). Millennials in the Workplace: A Conceptual Analysis of Millennials' Leadership and Followership Styles. International Journal of Human Resource Studies, 2(2), 71-83. doi: 10.5296/ijhrs.v2i2.1568

[9] Cropanzano, R., \& Mitchell, M. S. (2005). Social Exchange Theory: An Interdisciplinary Review. Journal of Management, 31(6), 874-900. doi: 10.1177/0149206305279602

[10] Dartey-Baah, K. (2015). Resilient leadership: a transformationaltransactional leadership mix. Journal of Global Responsibility, 6(1), 99-112. doi: 10.1108/jgr-07-2014-0026

[11] Hangeior, A. A., Ihagh, I. F., \& Esiebugie, U. M. (2016). Effect of Relational Leadership on Organizational Effectiveness in the Nigerian Public Sector: A Study of Power Holding Company of Nigeria . Imperial Journal of Interdisciplinary Research, 2(8), $1326-1332$.

[12] Ibrahim, M. Y. (2015). Model of Virtual Leadership, Intra-team Communication and Job Performance Among School Leaders in Malaysia. Procedia - Social and Behavioral Sciences, 186, 674680. doi: $10.1016 /$ j.sbspro.2015.04.126

[13] Iriqat, R. A. M., \& Khalaf, D. M. S. (2017). Using E-Leadership as a Strategic Tool in Enhancing Organizational Commitment of Virtual Teams in Foreign Commercial Banks in North West Bank -Palestine. International Journal of Business Administration, 8(7), 25-32. doi: 10.5430/ijba.v8n7p25
[14] Mansor, Z. D., Mun, C. P., Farhana, B. S. N., \& Tarmiz, W. A. N. W. M. (2017). Influence of Transformation Leadership Style on Employee Engagement among Generation Y. International Journal of Social, Behavioral, Educational, Economic, Business and Industrial Engineering, 11(1), 161-165.

[15] Mohammad, K. (2009). E-Leadership: The Emerging New Leadership for the Virtual Organization. Journal of Managerial Sciences, 3(1).

[16] Monahan, K. (2012). A Review of the Literature Concerning Ethical Leadership in Organizations. Emerging Leadership Journeys, 5(1), 56-66.

[17] Moorthy, R. (2014). An Empirical Study of Leadership Theory Preferences among Gen $Y$ in Malaysia. Review of Integrative Business \& Economics Research, 3(2), 398-421.

[18] Moreno, F. M., Lafuente, J. G., Carreón, F. Á., \& Moreno, S. M. (2017). The Characterization of the Millennials and Their Buying Behavior. International Journal of Marketing Studies, 9(5), 135 144. doi: $10.5539 /$ ijms.v9n5p135

[19] Perry, A., \& Hammond, N. (2002). Systematic Reviews: The Experiences of a PhD Student. Psychology Learning \& Teaching, 2(1), 32-35. doi: 10.2304/plat.2002.2.1.32

[20] Putriastuti, B. C. K., \& Stasi, A. (2019). HOW TO LEAD THE MILLENNIALS: A REVIEW OF 5 MAJOR LEADERSHIP THEORY GROUPS. Journal of Leadership in Organizations, 1(2), 96-111. doi: 10.22146/jlo.46562

[21] Ratcliffe, J., \& Ratcliffe, L. (2015). Anticipatory Leadership and Strategic Foresight : Five ' Linked Literacies .' Journal of Futures Studies, 20(September), 1-18. doi: 10.6531/JFS.2015.20(1).A1

[22] Salahuddin, M. M. (2010). Generational Differences Impact On Leadership Style And Organizational Success. Journal of Diversity Management (JDM), 5(2), 1-6. doi: $10.19030 / j d m . v 5 i 2.805$

[23] Solaja, O. M., \& Ogunola, A. A. (2016). Leadership Style and Multigenerational Workforce: A Call for Workplace Agility in Nigerian Public Organizations. International Journal of African and Asian Studies, 21, 46-56.

[24] Valenti, A. (2019). Leadership Preferences of the Millennial Generation. (2019). Journal of Business Diversity, 19(1). doi: 10.33423/jbd.v19i1.1357

[25] Vasconcelos, S. C., Frazão, I. da S., Monteiro, E. M. L. M., Lima, M. D. da C., Albuquerque, J. F. de, \& Ramos, V. P. (2013). Nursing Interventions for Drug Users: Qualitative MetaSynthesis. American Journal of Nursing Research, 1(1), 24-27. doi: 10.12691/ajnr-1-1-4

[26] Wahono, R. S. (2015). A Systematic Literature Review of Software Defect Prediction: Research Trends, Datasets, Methods and Frameworks. Journal of Software Engineering, $1(1)$

[27] Wolor, C. W., Pratama, A., Aditya, S., F, N. F., \& Purwana, D. (2020). Adversity Quotient In Improving Millennial Generation Salespeople's Performance In The Industrial Revolution. Humanities \& Social Sciences Reviews, 8(1), 220-226. doi: 10.18510/hssr.2020.8131

[28] Yozgat, U., \& Meşekıran, G. (2016). The Impact of Perceived Ethical Leadership and Trust in Leader on Job Satisfaction. Journal of Economics, Business and Management, 4(2), 125131. doi: $10.7763 /$ joebm.2016.v4.378 